\title{
AGRICULTURA FAMILIAR: O TRABALHO DOS JOVENS NA GESTÃO E REPRODUÇÃO DE UM MODO DE VIDA NA REGIÃO ALTO URUGUAI, RIO GRANDE DO SUL
}

\author{
FAMILY FARMING: THE WORK OF YOUNG PEOPLE IN THE MANAGEMENT \\ AND REPRODUCTION OF A WAY OF LIFE IN THE ALTO URUGUAI REGION, \\ RIO GRANDE DO SUL
}

\section{LA AGRICULTURA FAMILIAR: EL TRABAJO DE LOS JÓVENES EN LA GESTIÓN Y REPRODUCCIÓN DE UNA FORMA DE VIDA EN LA REGIÓN DE ALTO URUGUAI, RIO GRANDE DO SUL}

\author{
Zenicleia Angelita Deggerone - Emater - Porto Alegre - Rio Grande do Sul - Brasil \\ zenicleiadeggerone@gmail.com
}
Luís Fernando da Silva Laroque - Centro Universitário Univates - Lajeado - Rio Grande do Sul - Brasil Iflaroque@terra.com.br

\author{
Júlia Elisabete Barden - Centro Universitário Univates - Lajeado - Rio Grande do Sul - Brasil \\ jbarden@univates.br
}

\section{Resumo}

A agricultura familiar caracteriza-se como um modo de vida que vem se diferenciando pela preservação da biodiversidade e manutenção da identidade sociocultural das comunidades rurais, situação que ocorre também no Rio Grande do Sul. Considerando este contexto, o estudo objetiva analisar o processo social de permanência dos jovens rurais nas unidades de produção familiares nos municípios de Aratiba e Itatiba do Sul, localizados na Região Alto Uruguai, Rio Grande do Sul. A pesquisa, caracterizada como qualitativa, utilizou informações que foram obtidas em diários de campo e entrevistas com jovens que atuam nas atividades econômico-produtivas nas unidades de produção familiares em análise. Dentre as constatações, observou-se que a permanência dos jovens no meio rural está relacionada a fatores como a autonomia e o poder de decisão dos jovens na propriedade rural; a retribuição monetária pelas atividades desenvolvidas pelos jovens; as responsabilidades assumidas pelos jovens nos trabalhos e na gestão da propriedade rural; a valorização do trabalho realizado pelas jovens mulheres; a viabilidade econômica da unidade de produção através da diversificação dos sistemas de produtivos; a obtenção de rendas complementares (pluriatividade) às atividades agropecuárias, pelos jovens; e a inserção de novas atividades produtivas (agroindústrias familiares) na unidade de produção familiar.

Palavras-chave: agricultura familiar, jovens rurais, reprodução social.

\section{Abstract}

Family farming is a way of life that has presented its differential due to the preservation of biodiversity and the maintenance of socio-cultural identity of rural communities, a situation that also occurs in Rio Grande do Sul. Considering this context, this study aims to analyze the social process of rural youngsters' permanence inside family production units in the municipalities of Aratiba and Itatiba do Sul, located in the Alto Uruguai Region, Rio Grande do Sul. The research is characterized as qualitative, used information that was obtained in field diaries and interviews with young people who work in the economic-productive activities in family production units under review. Among the findings, it was observed that the permanence of rural youth is related to factors such as the autonomy and empowerment of young people in the rural property; the 
monetary retribution for activities developed by young people; the responsibilities assumed by the youth in the work and management of rural property; the valuation of the work performed by young women, the economic viability of the production unit through diversification of the production systems, the achievement of additional income (multiple activities) the agricultural activities by young people and of the insertion of new productive activities (family agribusinesses) in the family production unit.

Key words: family farming, rural youth, social reproduction.

\section{Resumen}

La agricultura familiar se caracteriza por ser una forma de vida en que hay la diferenciación por la preservación de la biodiversidad y el mantenimiento de la identidad sociocultural de las comunidades rurales, situación que también hay en Rio Grande do Sul. Teniendo en cuenta este contexto, el estudio tiene como objetivo analizar el proceso social de la permanencia de los jóvenes rurales en las unidades de producción familiar en los municipios de Aratiba y Itatiba do Sul, ubicadas en la región de Alto Uruguai, Rio Grande do Sul. La investigación se caracteriza como información cualitativa, que se emplea obtenida en diarios de campo y entrevistas con los jóvenes que trabajan en las actividades económico-productivas en las unidades de producción familiar en análisis. Entre los resultados, se observó que la permanencia de los jóvenes en el medio rural, esta relacionada a factores como la autonomía y el empoderamiento en la granja; la retribución monetaria para las actividades desarrolladas por los jóvenes; las responsabilidades encargadas a los jóvenes en los cargos y en la gestión de la granja; del reconocimiento del labor desarrollado por las jóvenes mujeres; de la viabilidad económica de la explotación a través de la diversificación de los sistemas productivos; de la obtención de ingresos adicionales (pluriactividades) a las actividades agrícolas por los jóvenes y la introducción de nuevas actividades productivas (agronegocios familiares) en la unidad de producción familiar.

Palabras clave: agricultura familiar, jóvenes rurales, reproducción social.

\section{Introdução}

A agricultura familiar caracteriza-se como um modo de vida diferenciado pela preservação da biodiversidade e manutenção da paisagem rural, identidade cultural e manutenção do tecido social das comunidades rurais, além da produção de alimentos e, consequentemente, assegura a continuidade dessas ações pelos jovens descendentes de famílias de agricultores.

A juventude está presente na reprodução social das famílias rurais e se insere no estabelecimento agrícola através do trabalho, ou seja, caracteriza-se pela "unidade de produção agrícola onde propriedade e trabalho estão intimamente ligados à família” (Lamarche, 1993, p. 15).

As relações familiares, aliadas aos trabalhos desenvolvidos, são responsáveis pela condição socioeconômica da família rural e a juventude contribui decisivamente com a mão de obra, com aspectos relacionados ao acesso, à adesão e constituição de novas fontes de renda, considerando-se a perspectiva do investimento em capital social e a viabilidade produtiva no que diz respeito ao desenvolvimento no meio rural. Dessa forma, este trabalho tem como objetivo analisar o processo social da permanência 
dos jovens rurais nas unidades de produção familiares, nos municípios de Aratiba e Itatiba do Sul, localizados na Região Alto Uruguai (RS), através da participação deles nas atividades econômico-produtivas nas unidades de produção agrícolas.

A abordagem do estudo caracteriza-se pela metodologia qualiquantitativa que, segundo Rampazzo (2002), requer uma busca do pesquisador em relação aos contextos histórico, geográfico, social, econômico e cultural dos atores sociais a serem estudados. Assim, quanto mais inserido em um aspecto do problema, maior a capacidade de percepção e análise de informações, considerando as questões particulares, o subjetivismo e a autenticidade do objeto em estudo. Os procedimentos metodológicos consistiram na análise das informações obtidas na pesquisa bibliográfica e em campo, em 2013, com a aplicação de questionários semiestruturados às famílias para a caracterização socioeconômica produtiva da unidade de produção familiar e aos jovens para a sua caracterização sociocultural, em quatro unidades de produção familiares (UPFs), no município de Aratiba, e três unidades de produção familiar no municipío de Itatiba do Sul, com a participação efetiva de vinte pessoas. Vale destacar que esses municípios estão localizados em territórios da Região Alto Uruguai, porção norte do Rio Grande do Sul, nos quais há jovens atuando nas atividades produtivas, em suas propriedades rurais.

\section{0 novo rural e as diferentes formas de organização e reprodução social das famílias}

As transformações ocorridas na agricultura, que se iniciaram com o advento do capitalismo, com a industrialização do campo e com a expansão urbana, foram responsáveis pela criação de novos cenários de sociabilidade e de trabalho. As múltiplas atividades agrícolas, dentre as quais podem ser citadas a produção de alimentos de qualidade, a preservação dos recursos ambientais e do patrimônio histórico e cultural do campo, a agroindustrialização em unidades familiares e o turismo rural, formam a multifuncionalidade da agricultura familiar, o que é importante no contexto socioeconômico.

No meio agrícola, observa-se a redução da natalidade, cuja tendência é de, em média, dois a três filhos por família. Conforme dados do DIEESE (2013), em 1960, a média era de seis filhos por família. Em 2010, a estatística apontou um decréscimo preocupante: a média de 1,8 filho por 
família agrícola. No Rio Grande do Sul, há 378 mil unidades de produção familiares e a população jovem é de 336 mil, na faixa etária entre 15 e 29 anos, em atividade no meio rural. Com base nesses índices, identifica-se que há menos de um jovem por unidade familiar, o que determina que nem todas as propriedades terão sucessão geracional. No entanto, a pesquisa demonstra que há, no mínimo, um sucessor para cada estabelecimento agrícola nas unidades produtivas de Aratiba e Itatiba do Sul, e que há o empenho das famílias agrícolas para que os demais jovens também as sucedam nessas atividades.

A permanência dos jovens no meio rural está relacionada à capacidade de absorção de mão de obra e à superfície de área útil disponível para o exercício dessas atividades produtivas. Os dados observados nos questionários referentes à caracterização socioeconômica produtiva, nas UPFs, determinam que as áreas rurais apresentam a extensão de 8,6 ha a 38,0 ha, usadas em atividades de criação animal e vegetal. Em Aratiba, há a criação de aves de corte e a produção de grãos; já em Itatiba do Sul, os jovens desenvolvem atividades de processamento agroindustrial de farináceos, pasteurização do leite e produção de queijos.

A produção de olerícolas, frutas, a bovinocultura leiteira e o cultivo de alimentos para o autoconsumo são atividades desenvolvidas em ambos os municípios em estudo. Ressalta-se que os produtos de origem vegetal (milho, trigo, soja, aveia e parte das frutas) e os de origem animal (carne de aves e leite in natura) são encaminhados para o processamento e a comercialização em outros municípios. Nos registros de Diário de Campo (09/3/13, 16/3/13 e 16/3/13a), observa-se que os produtos olerícolas, parte das frutas e a produção das agroindústrias familiares abastecem os mercados locais e os mercados institucionais do Programa Nacional de Alimentação Escolar (PNAE) e Programa de Aquisição de Alimentos (PAA); o excedente dessa produção é comercializado em escala regional, através dos centros de distribuição e comercialização.

De acordo com os dados coletados, ressalta-se a variabilidade de estratégias utilizadas pelas famílias e pelos jovens, com o intuito de aumentar a produção familiar, destacando-se a viabilidade econômica da unidade de produção, através das atividades agrícolas e consequente estabilidade financeira que pode ser obtida com a diversificação produtiva.

Nesse contexto, a produção agroindustrial representa uma inovação e uma forma de reprodução social em relação aos agricultores familiares, com maior autonomia (Long, 2006). O processo de agroindustrialização 
gera o aumento de conhecimento e informação dos agricultores, em virtude do relacionamento com outros trabalhadores e com as instituições. A busca de informação permite a inserção do jovem no sistema gestor da unidade produtiva, promove o diálogo e a tomada de decisões em conjunto, atitudes preponderantes para que o jovem agricultor permaneça no campo.

A pesquisa demonstrou um aspecto relevante quanto à produção para o autoconsumo: a existência de hortas domésticas e pomares, considerados como "produção para o gasto". Em Aratiba e em Itatiba do Sul, há maior produção de olerícolas, que são comercializadas no local, além da sua utilização para o autoconsumo. Essa atividade é observada como estratégia de desenvolvimento, interligada à internalização de recursos, maximização daqueles disponíveis na unidade familiar e à coprodução associada à artesanalidade do trabalho familiar (Ploeg, 2004).

Nesse sentido, a produção para o autoconsumo está associada fundamentalmente à busca dos agricultores por autonomia em relação ao controle da produção e à qualidade dos alimentos destinados ao consumo familiar. A geração de renda determina a pluriatividade e viabiliza a permanência das famílias no meio rural; além disso, há o uso de mão de obra no meio urbano.

Os registros, nos Diários de Campo (9/3/13, 16/3/13 e 16/3/13a), mostram que os jovens, em Aratiba e Itatiba do Sul, exercem duas ocupações com o propósito de aumentar a renda financeira mensal, o que determina maior poder aquisitivo; fazer investimentos futuros, como a aquisição de terras; e contribuir com as despesas da UPF. Nesse contexto, a pluriatividade exercida por eles, nas UPFs dos dois municípios, é responsável pelas estratégias de diversificação socioeconômica de atividades não agrícolas, para complementar a renda agrícola e promover a capitalização das propriedades; em consequência, mantém o agricultor em sua propriedade.

A contribuição de renda e a aplicabilidade pelos jovens nas UPFs variam, ou seja, a renda líquida, nessas unidades, apresenta-se entre R \$ 2.573,00 e R\$ 6.102,00. Constata-se, nos questionários de caracterização socioeconômica produtiva, que eles desenvolvem atividades pluriativas - atividades não agrícolas fora da unidade de produção. Ressalta-se a existência de dois casos em que os jovens recebem um percentual de produção anual ou valor mensal, variando entre $\mathrm{R} \$ 300,00$ e $\mathrm{R} \$ 600,00$. 
A remuneração dos jovens agricultores, oriunda das atividades produtivas nas UPFs, determina o incentivo e a valorização dessa mão de obra na produção agrícola, gerando a sua independência financeira, a autonomia e o protagonismo. Existem aspectos positivos quanto à remuneração dos jovens, comparada ao padrão costumeiro na agricultura familiar. Silva e Capello (2005) afirmam que, apesar da forma de organização do trabalho na agricultura familiar sem equacionar a renda proveniente do trabalho coletivo, há a tendência do pagamento de algum tipo de remuneração para os jovens, o que é importante em relação à sua permanência no trabalho familiar.

De acordo com a pesquisa realizada, essa situação indica a valorização do trabalho dos jovens nos estabelecimentos e nas agroindústrias, proporcionando a independência financeira e o interesse dos familiares na sucessão agrícola. A partir daqui, serão apresentados alguns relatos de pais e de jovens trabalhadores das UPFs, em que aparecem apenas as iniciais de seus nomes. As entrevistas, feitas em 2013, foram concedidas aos autores deste artigo e gravadas. Estas narrativas dos entrevistados demonstram como se dá a sua relação com o trabalho, o dinheiro, o lazer e quais são as expectativas futuras.

A busca pela autonomia e pela unidade de produção são itens apontados por um dos pais, conforme descrito:

Porque uma vez com 18 anos a gente já tinha um dinheirinho para compra a nossa terra e áreas agrícolas para escolher. Só que hoje, os jovens não têm dinheiro e nem áreas produtivas para adquirir, daí ele vai para a cidade em vez de ir para a sua propriedade rural. (EL, 9/3/2013, p. 4)

Na retomada do período histórico das famílias, os pais, quando jovens, já tinham poder aquisitivo para adquirir uma gleba de terra agregada à propriedade familiar, ou seja, tinham condições financeiras para comprar uma propriedade rural para seus descendentes, a fim de constituir uma nova família. Carneiro (1998) afirma que a saída dos jovens do meio rural significa uma necessidade de reprodução social e as principais causas dessa evasão da propriedade familiar devem-se à escassez de terras, em razão da progressiva ocupação de espaços, e ao esgotamento da fronteira agrícola.

Uma das preocupações dessas pessoas do meio rural está relacionada à necessidade de manutenção da unidade produtiva e reprodução 
social da família. Ao longo dos anos, desencadeou-se a comercialização de glebas de terras pelas famílias que permaneceram no campo, em geral compostas por um casal idoso sem condições físicas para realizar as tarefas agrícolas, cujos filhos não permaneceram no meio rural. Nesse caso, as glebas são comercializadas a preços elevados; quem as adquire são pessoas que já possuem uma boa estabilidade econômica e buscam a ampliação do capital. Decorrente disso, é preciso impedir a concentração da terra e desenvolver mecanismos de acesso a ela, a partir de políticas públicas fundiárias.

$\mathrm{O}$ acesso à renda é um dos fatores condicionantes da autonomia e valorização da presença dos jovens nas UPFs, em Aratiba e Itatiba do Sul. Essas informações, quantificadas com base nos questionários de caracterização socioeconômica da unidade de produção familiar, indicam que a maioria dos jovens utiliza seus recursos financeiros primeiro com as despesas em lazer e entretenimento; posteriormente é que eles usam seu dinheiro para adquirir bens de uso pessoal. Em terceiro lugar, guardam os valores em agências bancárias, para adquirir a sua unidade de produção no futuro; ajudar a complementar a renda familiar e aplicar os recursos financeiros em estudos (cursos técnicos, cursos de curta duração etc.). Dentre os gastos, apenas um jovem também utiliza parte dos recursos financeiros para o pagamento de dívidas contraídas pela família e para se preparar para o casamento.

Os jovens agricultores familiares, de modo geral, tendem ao investimento inicial em anseios pessoais, característica desse período que os integram aos demais grupos. A indústria da cultura, conforme Weisheimer (2005), visa ao lucro e é responsável pelo consumismo em relação à moda, música e aos acessórios, incentivados especialmente pela mídia, a qual o jovem agricultor tem acesso na atualidade.

No que se refere a determinados aspectos do trabalho, foram observadas as questões relacionadas à especialização produtiva das atividades agropecuárias, pois, em alguns casos, tais atividades exigem maior capacidade de aprendizagem e mais comprometimento durante a execução das tarefas e o jovem pode desempenhá-las com mais atenção, uma vez que as exercem com maior autonomia delegada pelos pais. Essas circunstâncias são relatadas por um dos jovens agricultores entrevistados:

As tecnologias e as novas técnicas de produção exigem da família mais dedicação e especialização produtiva. E os pais demonstram 
uma menor habilidade de aprendizagem e comprometimento, daí eles delegam aos filhos a liberdade de executarem estas atividades. (EP, 13/7/2013, p. 1)

Em consequência, os jovens buscam qualificação em determinadas atividades e práticas agropecuárias, obtendo aprendizagem mais rápida, com maior receptividade em relação às práticas inovadoras e com o aumento de qualidade e quantidade da produção nas unidades familiares.

A segunda questão refere-se ao controle dos registros das atividades produtivas, conforme o depoimento de um jovem que desenvolve a atividade de bovinocultura leiteira na unidade produtiva; ele afirma que "fizemos um pequeno controle, até porque a atividade leiteira pede que a gente leve tudo controlado [...], sobre a quantidade da ração, proteína, sal, vacinas, que se deve dar aos animais" (EB, 16/3/2013, p. 9).

Nas agroindústrias familiares, os jovens também realizam essas ações. Um deles relatou que "eu controlo uns custos da agroindústria, pois é importante a gente saber o quanto dá para ser investido" (EF. 16/3/2013, p. 5).

Os jovens agricultores familiares notam que a permanência no meio rural e a dedicação aos trabalhos relacionados ao cultivo de grãos, pecuária ou setor agroindustrial dependem da observância do comportamento dos mercados agroindustriais. Nesse sentido, cita-se Carrion (2005), que relaciona a postura do jovem agricultor à postura de um empreendedor rural, com a visão de oportunidades, necessidades de mercado, riscos assumidos e habilidade para recomeçar sempre que necessário.

A competência individual dos jovens, com o intuito de ampliar seus conhecimentos e suas práticas gestacionais, é importante para o fortalecimento da liderança, relacionada às transformações sociais, políticas e econômicas necessárias para a dinâmica e compreensão do mercado em que estão inseridos. Eles realizam várias atividades, que envolvem desde a produção até a gestão de recursos, tais como cuidados com a horta e o pomar, a comercialização de produtos agrícolas e agroindustriais, participação em reuniões e cursos técnicos, execução de serviços bancários (depósito ou retirada de recursos financeiros), tomada de decisões sobre investimentos em novas tecnologias, equipamentos e destinação de recursos financeiros nas UPFs. Além disso, desenvolvem atividades pontuais: manejo sanitário, preparo da alimentação, ordenha de animais, limpeza de equipamentos, conserto de móveis e instalações, compra de insumos para a utilização nas unidades de produção familiares. 
A tomada de decisão pelos jovens é assunto de destaque na pesquisa efetivada, visto que as jovens têm dupla jornada, isto é, elas conciliam as atividades domésticas com as do trabalho agroindustrial e a agropecuária. A tomada de decisão baseia-se no bom senso e no conhecimento do agricultor, em consonância com os objetivos idealizados; consequentemente, segundo Dalcin (2010), a gestão agrícola confere lógica e racionalidade aliadas à tradição, ao aprendizado, à infraestrutura e aos aspectos psicológicos, sociais e econômicos.

Aguiar e Stropasolas (2010) observaram que o envolvimento das moças no processo de tomada de decisão é maior, menor ou nula, de acordo com a intensidade de sua participação nas atividades consideradas "produtivas" para a unidade familiar. Dessa forma, quando as filhas desenvolvem somente atividades domésticas, a participação em tomada de decisão é nula. Porém, quando participam das demais áreas de produção, elas também tomam parte nas decisões em maior intensidade, o que contribui para a sua permanência no meio rural.

Conforme Boni (2006), não há disparidade quanto ao trabalho no meio rural, mas as mulheres têm maior responsabilidade com os serviços domésticos. Para Wanderley (2007), os rapazes estão ausentes nos serviços domésticos, já a maioria das moças realiza a dupla jornada: cuidar da casa e trabalhar na unidade produtiva familiar.

A continuidade da reprodução social do modo de vida envolve o processo de herança do patrimônio familiar, ou seja, existe a transferência legal da terra e dos ativos produtivos da unidade familiar. Quanto a essa situação, os pais entrevistados na pesquisa declaram que a transferência da terra e dos recursos disponíveis nas unidades de produção familiares destina-se, inicialmente, aos filhos que permanecem no meio rural, mas pretendem que não haja a fragmentação da propriedade rural no momento da partilha, pois esse fato pode inviabilizar a prática de certas atividades produtivas. Há a tendência para que todos os herdeiros tomem posse da terra, porém há circunstâncias em que somente o filho mais velho vai permanecer na unidade familiar; assim, os demais filhos receberão o montante condizente com o valor do capital da família. Um entrevistado declara que "ah, provavelmente vamos dar alguma outra coisa do mesmo valor na cidade ou em outro local, igualando o valor da terra, para quem ficar na propriedade" (EL, 9/3/2013, p. 3-4).

De acordo com Silvestro et al. (2001), faz-se necessária a igualdade no processo sucessório, tendo em vista a premência de investimentos na pro- 
priedade e a definição de valores e formas de pagamento aos filhos não contemplados com a área rural paterna. Embora o diálogo esteja presente nas famílias em questão, os temas sobre a sucessão são raramente abordados, conforme o depoimento de um entrevistado, ao afirmar: "bom, não tocamos no assunto, mas vai ser dividido em partes iguais” (EE, 16/3/2013, p. 3).

Em Itatiba do Sul, a divisão da propriedade entre os sucessores é uma realidade, mas a exceção ocorre em uma família, em que uma moça namora um jovem agricultor de outro município e, provavelmente, migrará para a nova unidade familiar; por meio dessa união, ocorrerá a implantação de uma nova agroindústria de farináceos:

Ela tá quase indo embora, porque ela vai casar e irá morar no interior [...], e lá será feita uma nova agroindústria, que nós vamos ajudar a construir como herança, porque nossa área de terra é pequena, então esta será a forma de recompensa. Já, os outros filhos, pretendemos aí comprar mais um pedaço de terra [...], e depois a gente divide, a escolha é deles, mas todos têm direito do capital. (EC, 23/3/2013, p. 3)

Nas respostas concedidas pelos pais, predomina uma expectativa de herança igualitária para os jovens e está em conformidade com os dispositivos legais que reconhecem todos os filhos, independente do sexo, como detentores com direitos iguais à herança dos pais, o que representa um importante avanço no que se refere ao reconhecimento de todos os filhos.

A pesquisa identificou a preocupação de um dos pais acerca da divisão da unidade familiar. Ele afirmou que "ela também irá receber uma parte, porque antigamente as meninas não ganhavam nada” (EE, 16/3/2013, p. 4). Esse fato demonstra a forma de pensar e o comportamento modificados mediante os padrões morais idealizados pela sociedade de Alto Uruguai. Assim, a permanência no meio rural é incentivada com essas medidas e o reconhecimento pela família de que todos os filhos são herdeiros da unidade produtiva constitui um avanço.

\section{Considerações finais}

O jovem agricultor familiar, nos dias atuais, pode dar continuidade a um modo de vida, por meio da reprodução social aliada ao desenvolvimento econômico da unidade produtiva, à preservação ambiental dos 
meios de produção, manutenção da segurança, soberania alimentar e às relações de sociabilidade entre atores sociais.

Constata-se que a forma de organização produtiva, caracterizada como agricultura familiar, mantém os componentes terra, trabalho e família para assegurar a independência da unidade econômica, a reprodução social e física do trabalho e da unidade de produção familiar. Dessa forma, as condições de permanência dos jovens, nos municípios de Aratiba e Itatiba do Sul, relacionam-se a alguns elementos como, por exemplo, à viabilidade econômica da unidade de produção que pode ser obtida através da diversificação dos sistemas produtivos.

As oportunidades e estratégias de obtenção de rendas complementares, nas atividades agropecuárias (pluriatividade), e a inserção de novas atividades (agroindústrias familiares) favorecem a atuação do jovem no desenvolvimento das atividades agrícolas.

A valorização dos jovens na execução das atividades produtivas, de forma que obtenham mais autonomia e poder de decisão, a retribuição monetária e a valorização da mão de obra são quesitos definitivos para a permanência deles no campo. Além disso, a valorização da mão de obra feminina, em sua dupla jornada de trabalho (doméstico e agrícola), é determinante para a sua autonomia e seu poder de decisão nas unidades de produção.

A qualificação e a formação de mão de obra jovem, para o exercício de algumas atividades produtivas, são importantes também, em razão da exigência de maior preparo para a sua integração nos mercados locais e regionais, uma vez que a formação possibilita o conhecimento de alternativas inovadoras tão necessárias ao crescimento econômico e social das famílias.

Através desta pesquisa, constata-se que os pais agricultores, na Região Alto Uruguai, têm a expectativa de herança e sua distribuição igualitária entre todos os filhos, independente do sexo, o que significa um importante avanço do seu modo de pensar e agir.

\section{Referências}

AGUIAR, V. V. P.; STROPASOLAS, V. L. As problemáticas de gênero e geração nas comunidades rurais de Santa Catarina. In: PARRY SCOTT, R. C.; MENEZES, M. (Orgs.). Gênero e geração em contextos rurais. 1. ed. Florianópolis: Mulheres, 2010. v. 1. p. 1-22. 
BONI, V. Gênero: o doméstico e o produtivo na agroindústria familiar. In: VII CONGRESSO LATINO AMERICANO DE SOCIOLOGIA RURAL, Quito. Anais... Quito/Equador, 2006.

CARNEIRO, M. J. O ideal rurbano: campo e cidade no imaginário de jovens rurais. In: SILVA, F. C. T.; SANTOS, R.; COSTA, L. F. C. Mundo rural e política: ensaios interdisciplinares. Rio de Janeiro: Campus, 1998.

CARRION, R. M. Reestruturação produtiva, organização e gestão do trabalho na indústria petroquímica: estudo do complexo petroquímico do Rio Grande do Sul. In: Associação Brasileira de Estudos do Trabalho. V Encontro Nacional. 2005. Disponível em: < http://www.race.nuca.ie.ufrj.br/abet/venc/artigos/38.pdf>. Acesso em: 18 maio 2007.

DALCIN, D. O processo de tomada de decisão em agricultores de Boa Vista das Missões/RS. 117 f. Dissertação (Mestrado em Extensão Rural) - Pós-Graduação em Extensão Rural, Universidade Federal de Santa Maria, Santa Maria, 2010.

DIEESE. Departamento Intersindical de Estatística e Estudos Socioeconômicos. Os desafios à ação sindical decorrentes das mudanças na população. São Paulo, n. 127, junho, 2013. Disponível em: <http://www.dieese.org.br/notatecnica/2013/ notaTec127demografia.pdf> Acesso em: 27 jul. 2013.

LAMARCHE, H. (Coord.). A agricultura familiar: comparação internacional. Tradução de Ângela Maria Naoko Tijiwa. Campinas: Ed. Unicamp, 1993.

LONG, N. Sociologia Del Desarollo: uma perspectiva centrada em el ator. Coleción Investigaciones: México. 504 p., 2006.

PESQUISA de CAMPO 2013. Questionário aplicado à família para caracterização socioeconômica produtiva da unidade de produção familiar, 2013.

$\overline{2} 0 \overline{13}$.

. Questionário aplicado aos jovens para sua caracterização sociocultural,

PLOEG, J. D. et al. Seeds of transition: essays on novelty production, niches and regimes in agriculture. Royal Van Gorcum, p. 1-28, 356p. 2004.

RAMPAZZO, L. Metodologia científica. São Paulo: Loyola, 2002.

SILVA, R. N.; CAPELO, M. R. C. Juventude do campo e políticas públicas: algumas reflexões de um texto em construção. Colloquium Humanarum, v. 3, n. 1, p. 3648, 2005.

SILVESTRO, M. L. et al. Os impasses sociais da sucessão hereditária na agricultura familiar. Florianópolis: Epagri; Brasília, DF: Nead/MDA, 2001.

WANDERLEY, M. N. B. Jovens rurais de pequenos municípios de Pernambuco: sonhos para o futuro. In: CARNEIRO, M. J.; CASTRO, E. G. de (Orgs.). Juventude rural em perspectiva. Rio de Janeiro: Mauad X, 2007. p. 21-34.

WEISHEIMER, N. Juventudes rurais: mapa de estudos recentes. Brasília: Ministério do Desenvolvimento Agrário, 2005. 
Zenicleia Angelita Deggerone - Graduada em Administração pela Universidade Estadual do Rio Grande do Sul, Especialista em Gestão e Manejo Ambiental em Agroindústrias pela Universidade Federal de Lavras, Mestre em Ambiente e Desenvolvimento pelo Centro Universitário Univates. Atualmente faz Especialização em Docência no Ensino Superior pelo Centro Universitário Leonardo da Vinci e é Colaboradora na Emater.

Luís Fernando da Silva Laroque - Graduado em Estudos Sociais e História pela Universidade do Vale do Rio dos Sinos, Mestre e Doutor em História pela mesma Universidade, Professor do Centro Universitário Univates.

Júlia Elisabete Barden - Graduada em Ciências Econômicas pela Universidade de Santa Cruz do Sul, Mestre em Economia Rural pela Universidade Federal do Rio Grande do Sul, Doutora em Economia com ênfase em Economia do Desenvolvimento pela mesma Universidade, Professora e Pesquisadora do Centro Universitário Univates.

Recebido para publicação em 5 de abril de 2014 Aceito para publicação em 28 de junho de 2014 